\title{
Implication of ARIMA Time Series Model on COVID-19 Outbreaks in India
}

\author{
D. Mallikarjuna Reddy
}

\begin{abstract}
This research paper focuses on a Time Series Model to predict COVID-19 Outbreaks in India. COVID-19 Corona virus disease has been recognized as a worldwide hazard, and most of the studies are being conducted using diverse mathematical techniques to forecast the probable evolution of this outbreak. These mathematical models based on various factors and analyses are subject to potential bias. Here, we put forward a natural Times Series (TS) model that could be very useful to predict the spread of COVID-19. Here, a popular method Auto Regressive Integrated Moving Average (ARIMA) TS model is performed on the real COVID-19 data set to predict the outbreak trend of the prevalence and incidence of COVID-19 in India. Every day data of fresh COVID-19 confirmed cases act as an exogenous factor in this frame. Our data envelops the time period from 12th March, 2020 to 27th June, 2020. The time series under study is a non-stationary. Results obtained in the study revealed that the ARIMA model has a strong potential for prediction. In ACF and PACF graphs. Lag 1 and Lag 40 was found to be significant. Regressed values imply Lag 1 and Lag 40 was significant in predicting the present trend. The model predicted maximum COVID-19 cases in India at around 14, 22,337 with an interval (12, 80,352 - 15, 69, 817) during 1st July to 30th July period cumulatively. As per the model, the number of new cases shall increases drastically in India only. The results will help governments to make necessary arrangements as per the estimated cases. This kind of investigation, implications of ARIMA models and fitting procedures are useful in forecasting COVID-19 Outbreaks in India.
\end{abstract}

Keywords: ARIMA, Time Series, COVID-19, ACF, PACF, Forecasting

\section{INTRODUCTION}

$\mathrm{N}$ ovel Virus belongs to Corona viruses' family that has been spread from animal to human beings and it was found in Wuhan, China, in December 2019. This can cause serious illness and even death too [1]. It's been identified as a Zoonotic corona virus, similar to severe acute respiratory syndrome corona virus (SARS-CoV) and Middle East Respiratory Syndrome Corona virus (MERS-CoV), and was named 2019-nCoV (2). The incidence scope of this illness is indistinguishable, since at present the occurrences of this virus infection are so dynamic [1]. There is clear variation among countries in epidemiological surveillance and detection capacity for suspected cases. Several cases of COVID-19 infections were also reported outside China [3]. Fore studies reveal that The first serious case of COVID-19

Revised Manuscript Received on July 15, 2020.

* Correspondence Author

D.Mallikarjuna Reddy*, Department of Mathematics, School of Science GITAM Deemed to be University, Hyderabad, India 502329: mallik.reddyd@gmail.com

(C) The Authors. Published by Blue Eyes Intelligence Engineering and Sciences Publication (BEIESP). This is an open access article under the CC BY-NC-ND license (http://creativecommons.org/licenses/by-nc-nd/4.0/) epidemic was reported by Chinese authorities along with WHO on 11th January 2020 whose features are similar to pneumonia of unknown origin that caused maximum spoil to developed countries similar to America, Spain, Russia, UK, Italy, France, Germany, Iron etc., affecting 215 countries and territories around the Globe. This COVID-19 pandemic decease has infected almost 10,097,334 people and caused deaths of 5, 01,585 people across the world till June 27th June, 2020. Around 5,473,348 people recovered also without any special treatment. Also in number 4,122,401 were currently infected patients from them 4,064,578 (99\%) in mild condition 57,823 (1\%) serious or critical stage 5, 974,933 cases which had an outcome that is about closed cases throughout world 5,473,348 (92\%) recovered and discharged and 5, 01, 585 (8\%). Deaths (https://www.worldometers.info/coronavirus). Where as in India the first case was reported on 15th February, 2020 [4] and thereafter it has been continued and reached to 5,29,889 cases with deaths 16,112 and Recovered case 3,10,236 with 58.54 percent recovery rate on 28th June, 2020 (https://www.worldometers.info/coronavirus/country/india). In this condition when the illness does not have any specific treatment, the prevention of disease and preparation in healthcare services is very important. Modeling and future forecast of daily number of confirmed cases can help the treatment system in providing services for the new patients. The statistical prediction models [5-6] could be helpful in forecasting and controlling this global epidemic threat. Here in this study, Auto Regressive Integrated Moving Average (ARIMA) model [7] could be constructive to predict confirmed cases of COVID-19. The best ARIMA model is identified, and then 60 future days (2-months) is predicted in India. Since the present trend is not supporting the results discussed in[4). The daily occurrence data of COVID-19 confirmed cases during 12th March, 2020 to 27th June, 2020 were collected from the official website of Govt. of India (https://www.mygov.in/covid-19) and were used to build these models. The purpose of this study is first to find the best predicting models for confirmed cases in the country. These models can suggest in predicting patients in near future to have better treatment in Indian hospitals. rectification is not possible.

\section{DESCRIPTION OF THE DATA}

Author (s) can send paper in the given email address of the journal. There are two email address. It is compulsory to send paper in both email address. The daily occurrence data of COVID-19 confirmed cases during 12th March, 2020 to 27th June, 2020 were collected from the official website of Govt. of India

\section{Published By:}

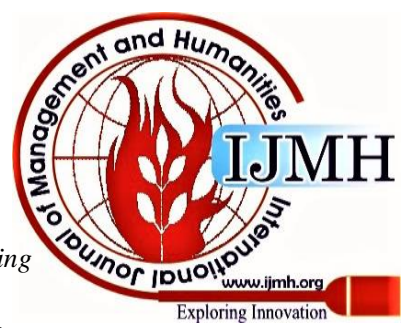




\section{Implication of ARIMA Time Series Model on COVID-19 Outbreaks in India}

(https://www.mygov.in/covid-19), and SPSS 20 software was used to build a time-series model Auto Regressive Integrated Moving Average (ARIMA) [1]. ARIMA model was applied to this dataset consisting of 108 rows day wise determinations cumulatively. Fig. 3 shows that the overall frequency of COVID-19 presented an increasing trend that is reaching the outbreaks in table. The difference between cases of one day and cases of the previous day $\Delta\left(\mathrm{Z}_{\mathrm{t}}-\mathrm{Z}(\mathrm{t}-1)\right)$ a variable increase in the number of confirmed cases. Descriptive analysis of the data was performed to evaluate the incidence of new confirmed cases of COVID-19 and to prevent eventual bias.

\section{Methodology -ARIMA (P,D,Q) MODEL}

The ARIMA model introduced by Box and Jenkins (1976) includes Autoregressive as well as moving average parameters and explicitly includes differencing in the formulation of the model. Specifically, the three types of parameters in the model are: the autoregressive parameters (p), the number of differencing passes (d), and moving average parameter (q). In the notation introduced by Box and Jenkins, models are summarized as ARIMA (p, d, q).

The foremost step in the process of modeling is to check for the stationary of the time series data. This is done by observing the graph of data or autocorrelation and the partial autocorrelation functions. Another way of checking stationary is to fit the first order AR model to the raw data and test whether the coefficient $\varnothing$ is less than one. The next step is to identify an appropriate sub-class of the general ARIMA model.

$$
\phi(B) \nabla^{d} Z_{t}=\theta(B) a_{t}
$$

Which may be used to represent a given time series.The general procedure is

(i) To difference $z_{t}$ as many times as is needed to produce stationary.

$\phi(B) \omega_{t}=\theta(B) a_{t}$

where $\omega_{t}=(1-B)^{d} Z_{t}=\nabla^{d} Z_{t}$

To identify the resulting ARIMA process. The Autocorrelation and Partial Autocorrelation functions will be used as main tools in attaining (i) and (ii) Stationary in time series means a constant mean, variance and Autocorrelation through time. Generally the hypothetical series will not be stationary. Therefore the series needs to differenced until it is stationary (usually at most two differences will be sufficient to make the series stationary).

$$
\omega_{t}=\nabla^{d} Z_{t}
$$

After differencing the series to identify the sub class of ARIMA model, which is suitable for the series, the components of Autoregressive (p) and Moving Average (q) should be identified. The number of parameters of Autoregressive (p) can be identified by using correlogram of partial autocorrelations and the number of parameters of moving average (q) can be identified by using correlogram of autocorrelations. Then p parameters of Autoregressive $\emptyset_{1}$, $\varnothing_{2},---, \emptyset_{p}$ and then q parameters of Moving Average $\theta_{1}$, $\theta_{2}$, - - - $\theta_{q}$ have to be estimated by using Least Squares (LS) or Maximum Likelihood (ML) methods.

\section{RESUlts \& Discussions}

To obtain the daily occurrences of COVID-19, ARIMA (p, d, q) was chosen as the top ARIMA model,[8]. Thus i.e ARIMA $(0,2,1)(p=0, d=2, q=1)$ has been fitted to forecast COVID-19 Confirmed Cases (Cumulative) using SPSS-20 and a fore study was taken as reference for the methodology of the analysis [9]. Logarithmic transformation was performed to evaluate the influence of seasonality on the forecast. The COVID-19 daily conformed new cases have been considered to identify the order of an moving average (MA) autoregressive (AR) model. A plot of the daily new COVID-19 cases against time is presented fig.1.

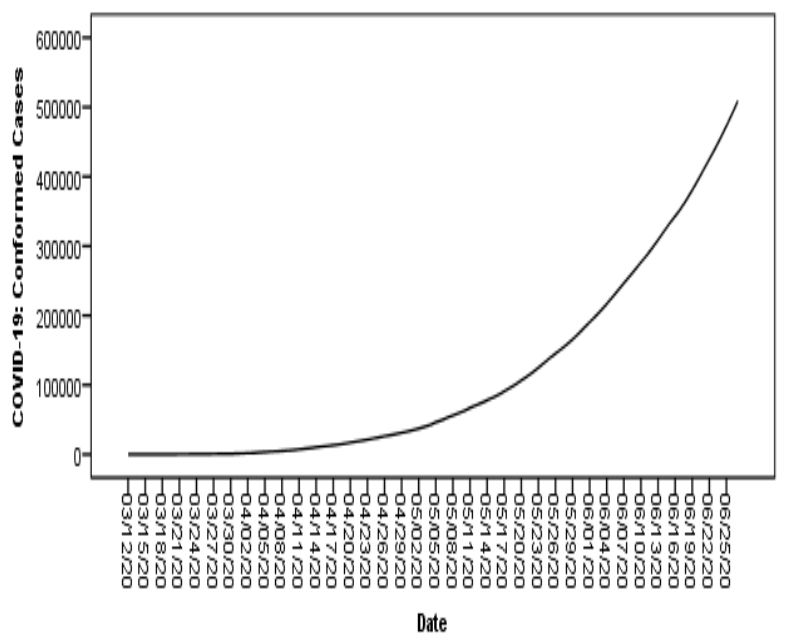

Fig. 1.Time Series plot of daily new Conformed COVID-19 cases

The correlogram(i.e ACFv/sLag) reporting the ACF and PACF [10] showed that significant thus Fig. 2 is the plot of autocorrelation function Graph of COVID-19 Daily new cases at 1st differencing. The Lag 1-lag16 all lags were showed significant and which was reported in Table 1 . The underlying process assumed is independence (white noise) and based on the asymptotic chi-square approximation. The statistical significance level was considered at 0.05 .

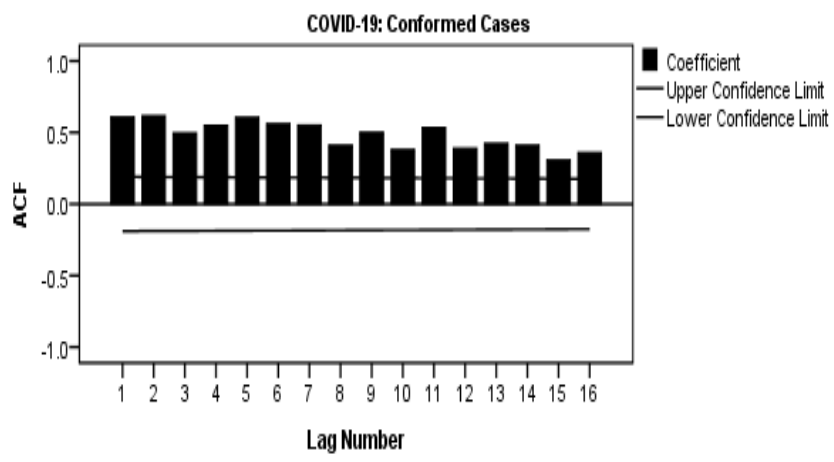

Fig. 2.Correlogram graph for the COVID-19 confirmed cases.

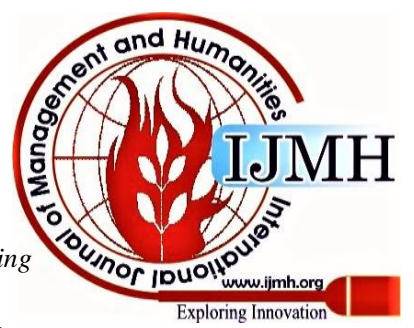


Table- I: Autocorrelations of COVID-19: Conformed Cases

\begin{tabular}{|c|c|c|c|c|c|}
\hline \multicolumn{5}{|c|}{ Autocorrelations } \\
\hline \multicolumn{5}{|c|}{ Series: COVID-19: Conformed Cases } \\
\hline \multirow{2}{*}{ Lag } & Autocorrelation & Std. Error & \multicolumn{3}{|c|}{ Box-Ljung Statistic } \\
\cline { 3 - 6 } & & & Value & df & Sig. $^{{ }^{\prime}}$ \\
\hline 1 & .608 & .095 & 41.054 & 1 & .000 \\
\hline 2 & .617 & .094 & 83.656 & 2 & .000 \\
\hline 3 & .497 & .094 & 111.555 & 3 & .000 \\
\hline 4 & .548 & .094 & 145.860 & 4 & .000 \\
\hline 5 & .606 & .093 & 188.203 & 5 & .000 \\
\hline 6 & .560 & .093 & 224.708 & 6 & .000 \\
\hline 7 & .551 & .092 & 260.468 & 7 & .000 \\
\hline 8 & .410 & .092 & 280.469 & 8 & .000 \\
\hline 9 & .501 & .091 & 310.561 & 9 & .000 \\
\hline 10 & .381 & .091 & 328.119 & 10 & .000 \\
\hline 11 & .533 & .090 & 362.925 & 11 & .000 \\
\hline 12 & .389 & .090 & 381.662 & 12 & .000 \\
\hline 13 & .423 & .089 & 404.055 & 13 & .000 \\
\hline 14 & .410 & .089 & 425.253 & 14 & .000 \\
\hline 15 & .307 & .088 & 437.329 & 15 & .000 \\
\hline 16 & .359 & .088 & 453.962 & 16 & .000 \\
\hline a. The underlying process assumed is independence (white noise) \\
\hline b. Based on the asymptotic chi-square approximation. \\
\hline
\end{tabular}

Fig. 3 is the plot of Partial autocorrelation function (PACF) Graph of COVID-19 daily conformed new cases at 1st Differencing In PACF graph. Lag 1 and Lag 16 is significant. regressed values imply Lag 1 and Lag 16 is significant in predicting the current values. All the Partial Autocorrelations of COVID-19: Confirmed Cases with Lag kept in Table-2. The models returned the highest stationary R2 and relatively lower BIC values showed in Table-3.

Table -5 shows the different parameters of autoregressive (p) and moving average (q) among the several ARIMA model experimented upon. ARIMA $(0,2,1)$ is considered best for COVID-19 prediction. The investigational results kept in Table -6 which are predicted values of ARIMA $(0,2,1)$ that has been found the best model for prediction of COVID-19 cases in India. Fig.4 reveals graphical visualization of predicted COVID-19 daily conformed cases in India.

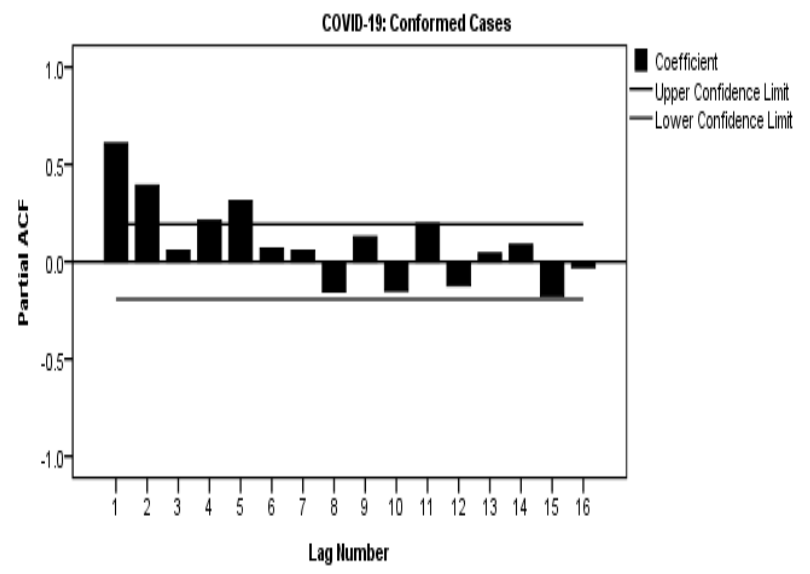

Fig.3 PACF for the COVID-19 confirmed cases

Table-II Partial Autocorrelations of COVID-19: Conformed Cases

\begin{tabular}{|c|c|c|}
\hline \multicolumn{3}{|c|}{ Partial Autocorrelations } \\
\hline Series: COVID-19: Conformed Cases \\
\hline Lag & Partial Autocorrelation & Std. Error \\
\hline 1 & .608 & .096 \\
\hline 2 & .392 & .096 \\
\hline 3 & .057 & .096 \\
\hline 4 & .211 & .096 \\
\hline 5 & .312 & .096 \\
\hline 6 & .069 & .096 \\
\hline 7 & .057 & .096 \\
\hline 8 & -.154 & .096 \\
\hline 9 & .128 & .096 \\
\hline 10 & -.149 & .096 \\
\hline 11 & .196 & .096 \\
\hline 12 & -.122 & .096 \\
\hline 13 & .044 & .096 \\
\hline 14 & .088 & .096 \\
\hline 15 & -.174 & .096 \\
\hline 16 & -.028 & .096 \\
\hline
\end{tabular}

Table- III: Model Fit of COVID-19: Confirmed Cases

\begin{tabular}{|c|c|c|c|c|c|c|c|c|c|c|}
\hline \multicolumn{11}{|c|}{ Model Fit } \\
\hline \multirow[t]{2}{*}{ Fit Statistic } & \multirow[t]{2}{*}{ Mean } & \multirow[t]{2}{*}{ Min. } & \multirow[t]{2}{*}{ Max. } & \multicolumn{7}{|c|}{ Percentile } \\
\hline & & & & 5 & 10 & 25 & 50 & 75 & 90 & 95 \\
\hline $\begin{array}{l}\text { Stationary } \\
\text { R-squared }\end{array}$ & 0.95 & 0.95 & 0.95 & 0.95 & 0.95 & 0.95 & 0.95 & 0.95 & 0.95 & 0.95 \\
\hline R-squared & 1 & 1 & 1 & 1 & 1 & 1 & 1 & 1 & 1 & 1 \\
\hline RMSE & 456.88 & 456.88 & 456.88 & 456.88 & 456.88 & 456.88 & 456.88 & 456.88 & 456.88 & 456.88 \\
\hline MAPE & 2.03 & 2.03 & 2.03 & 2.03 & 2.03 & 2.03 & 2.03 & 2.03 & 2.03 & 2.03 \\
\hline MaxAPE & 13.87 & 13.87 & 13.87 & 13.87 & 13.87 & 13.87 & 13.87 & 13.87 & 13.87 & 13.87 \\
\hline MAE & 310.72 & 310.72 & 310.72 & 310.72 & 310.72 & 310.72 & 310.72 & 310.72 & 310.72 & 310.72 \\
\hline MaxAE & 1615.84 & 1615.84 & 1615.84 & 1615.84 & 1615.84 & 1615.84 & 1615.84 & 1615.84 & 1615.84 & 1615.84 \\
\hline $\begin{array}{l}\text { Normalized } \\
\text { BIC }\end{array}$ & 12.337 & 12.337 & 12.337 & 12.337 & 12.337 & 12.337 & 12.337 & 12.337 & 12.337 & 12.337 \\
\hline
\end{tabular}


Implication of ARIMA Time Series Model on COVID-19 Outbreaks in India

Table- IV: Model Statistics of COVID-19: Confirmed Cases

\begin{tabular}{|c|c|c|c|c|c|c|}
\hline \multicolumn{7}{|c|}{ Model Statistics } \\
\hline \multirow[t]{2}{*}{ Model } & \multirow[t]{2}{*}{ Number of Predictors } & Model Fit statistics & \multicolumn{3}{|c|}{ Ljung-Box Q(18) } & \multirow{2}{*}{$\begin{array}{l}\text { Number of } \\
\text { Outliers }\end{array}$} \\
\hline & & $\begin{array}{l}\text { Stationary } \\
\text { R-squared }\end{array}$ & Statistics & DF & Sig. & \\
\hline COVID-19: Conformed Cases -Model_1 & 0 & .349 & 24.869 & 17 & .098 & 0 \\
\hline
\end{tabular}

Table- V: ARIMA Model Parameters

\begin{tabular}{|c|c|c|c|c|c|c|c|c|}
\hline & & & & & Estimate & SE & $\mathrm{t}$ & Sig. \\
\hline \multirow{3}{*}{$\begin{array}{l}\text { COVID-19: Conformed Cases } \\
\text {-Model_1 }\end{array}$} & \multirow{3}{*}{$\begin{array}{l}\text { COVID-19: } \\
\text { Conformed } \\
\text { Cases }\end{array}$} & \multirow{3}{*}{ Square Root } & \multicolumn{2}{|c|}{ Constant } & .115 & .024 & 4.720 & .000 \\
\hline & & & \multicolumn{2}{|c|}{ Difference } & 2 & & & \\
\hline & & & MA & Lag 1 & .720 & .070 & 10.283 & .000 \\
\hline
\end{tabular}

Table- VI ARIMA (p, d, q) forecast values of COVID-19 (Cumulative)

\begin{tabular}{|c|c|c|c|c|c|c|c|}
\hline \multirow[b]{2}{*}{ Model } & \multicolumn{3}{|c|}{ COVID-19: Confirmed Cases-Model_1(Cumulative) } & \multirow[b]{2}{*}{ Model } & \multicolumn{3}{|c|}{ COVID-19: Confirmed Cases-Model_1(Cumulative) } \\
\hline & Forecast & UCL & LCL & & Forecast & UCL & LCL \\
\hline $6 / 28 / 2020$ & 527187 & 529708 & 524671 & $8 / 1 / 2020$ & 1502402 & 1666926 & 1344338 \\
\hline $6 / 29 / 2020$ & 545913 & 550081 & 541756 & $8 / 2 / 2020$ & 1543689 & 1717161 & 1377202 \\
\hline $6 / 30 / 2020$ & 565139 & 571022 & 559278 & $8 / 3 / 2020$ & 1585829 & 1768537 & 1410656 \\
\hline $7 / 1 / 2020$ & 584874 & 592607 & 577179 & $8 / 4 / 2020$ & 1628834 & 1821071 & 1444709 \\
\hline $7 / 2 / 2020$ & 605129 & 614868 & 595448 & $8 / 5 / 2020$ & 1672713 & 1874778 & 1479369 \\
\hline $7 / 3 / 2020$ & 625911 & 637822 & 614084 & $8 / 6 / 2020$ & 1717481 & 1929677 & 1514643 \\
\hline $7 / 4 / 2020$ & 647230 & 661486 & 633091 & $8 / 7 / 2020$ & 1763149 & 1985782 & 1550540 \\
\hline $7 / 5 / 2020$ & 669096 & 685874 & 652474 & $8 / 8 / 2020$ & 1809728 & 2043111 & 1587068 \\
\hline $7 / 6 / 2020$ & 691518 & 710998 & 672241 & $8 / 9 / 2020$ & 1857232 & 2101680 & 1624235 \\
\hline $7 / 7 / 2020$ & 714505 & 736871 & 692398 & $8 / 10 / 2020$ & 1905671 & 2161507 & 1662050 \\
\hline $7 / 8 / 2020$ & 738067 & 763506 & 712952 & $8 / 11 / 2020$ & 1955059 & 2222609 & 1700520 \\
\hline $7 / 9 / 2020$ & 762214 & 790916 & 733911 & $8 / 12 / 2020$ & 2005408 & 2285001 & 1739654 \\
\hline $7 / 10 / 2020$ & 786956 & 819113 & 755281 & $8 / 13 / 2020$ & 2056730 & 2348702 & 1779461 \\
\hline $7 / 11 / 2020$ & 812301 & 848111 & 777071 & $8 / 14 / 2020$ & 2109038 & 2413730 & 1819949 \\
\hline $7 / 12 / 2020$ & 838261 & 877924 & 799286 & $8 / 15 / 2020$ & 2162345 & 2480100 & 1861126 \\
\hline $7 / 13 / 2020$ & 864845 & 908564 & 821935 & $8 / 16 / 2020$ & 2216662 & 2547831 & 1903002 \\
\hline $7 / 14 / 2020$ & 892064 & 940046 & 845025 & $8 / 17 / 2020$ & 2272004 & 2616941 & 1945584 \\
\hline $7 / 15 / 2020$ & 919926 & 972382 & 868563 & $8 / 18 / 2020$ & 2328382 & 2687447 & 1988881 \\
\hline $7 / 16 / 2020$ & 948443 & 1005587 & 892555 & $8 / 19 / 2020$ & 2385810 & 2759367 & 2032903 \\
\hline $7 / 17 / 2020$ & 977626 & 1039676 & 917011 & $8 / 20 / 2020$ & 2444301 & 2832718 & 2077658 \\
\hline $7 / 18 / 2020$ & 1007483 & 1074661 & 941935 & $8 / 21 / 2020$ & 2503868 & 2907520 & 2123155 \\
\hline $7 / 19 / 2020$ & 1038026 & 1110558 & 967337 & $8 / 22 / 2020$ & 2564523 & 2983789 & 2169403 \\
\hline $7 / 20 / 2020$ & 1069266 & 1147381 & 993223 & $8 / 23 / 2020$ & 2626281 & 3061545 & 2216410 \\
\hline $7 / 21 / 2020$ & 1101212 & 1185145 & 1019601 & $8 / 24 / 2020$ & 2689155 & 3140805 & 2264187 \\
\hline $7 / 22 / 2020$ & 1133877 & 1223864 & 1046477 & $8 / 25 / 2020$ & 2753157 & 3221588 & 2312741 \\
\hline $7 / 23 / 2020$ & 1167269 & 1263553 & 1073860 & $8 / 26 / 2020$ & 2818302 & 3303913 & 2362083 \\
\hline $7 / 24 / 2020$ & 1201401 & 1304227 & 1101757 & $8 / 27 / 2020$ & 2884603 & 3387797 & 2412221 \\
\hline $7 / 25 / 2020$ & 1236283 & 1345902 & 1130175 & $8 / 28 / 2020$ & 2952074 & 3473260 & 2463164 \\
\hline $7 / 26 / 2020$ & 1271927 & 1388592 & 1159122 & $8 / 29 / 2020$ & 3020728 & 3560321 & 2514923 \\
\hline $7 / 27 / 2020$ & 1308343 & 1432313 & 1188606 & $8 / 30 / 2020$ & 3090580 & 3648999 & 2567507 \\
\hline $7 / 28 / 2020$ & 1345542 & 1477081 & 1218634 & $8 / 31 / 2020$ & 3161643 & 3739312 & 2620924 \\
\hline $7 / 29 / 2020$ & 1383536 & 1522910 & 1249213 & 9/1/2020 & 3233930 & 3831279 & 2675184 \\
\hline $7 / 30 / 2020$ & 1422337 & 1569817 & 1280352 & 9/2/2020 & 3307457 & 3924921 & 2730298 \\
\hline $7 / 31 / 2020$ & 1461955 & 1617817 & 1312058 & $9 / 3 / 2020$ & 3382238 & 4020255 & 2786274 \\
\hline
\end{tabular}

For each model, forecasts start after the last non-missing in the range of the requested estimation period, and end at the last period for which non-missing values of all the predictors are available or at the end date of the requested forecast period, whichever is earlier.
Published By:

Blue Eyes Intelligence Engineering

\& Sciences Publication

(C) Copyright: All rights reserved.

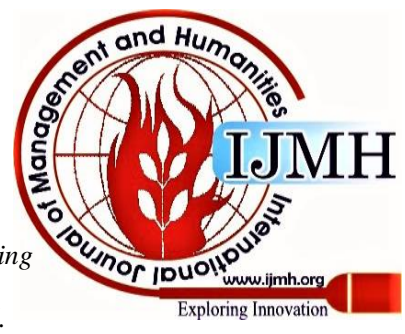




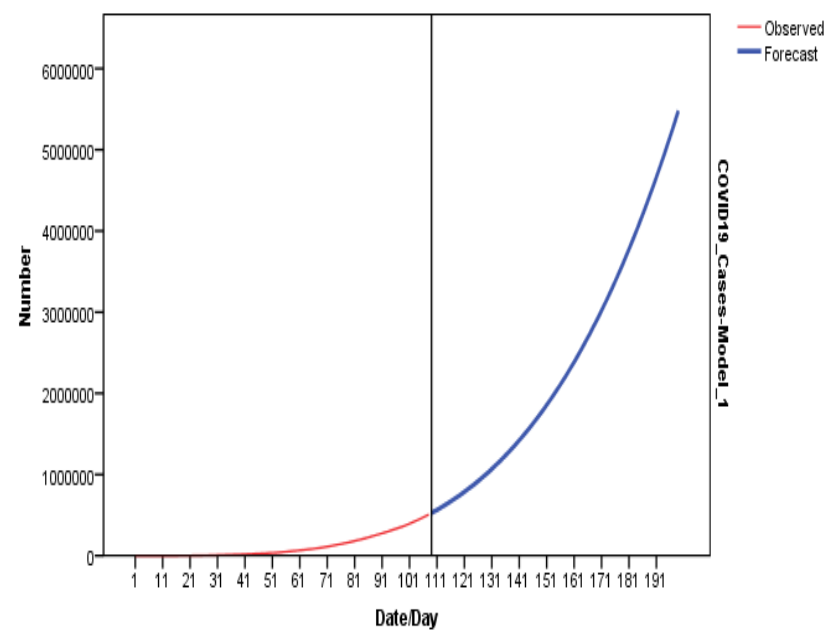

Fig.4 Forecasting COVID-19 confirmed cases (Cumulative) using ARIMA (0, 2, 1)

\section{CONCLUSION}

The results obtained with the model have been confirmed with the prospective of ARIMA models. The model implicated to predict COVID-19 cases on daily basis satisfactorily on short-term basis. The model predicted maximum COVID-19 cases in India at around 14, 61, 955 end of July 2020 within the range of $(13,12,058-16,17,817)$ with 95 percent confidence level. As per the model, the number of new cases shall increases drastically in India may be in the month of July and August 2020. The results will help governments to make necessary arrangements as per the estimated cases. This kind of analysis and implications of ARIMA models and fitting procedures are useful in forecasting COVID-19 Outbreaks in India..

\section{REFERENCES}

1. Paules CI, Marston HD, Fauci AS. Corona virus infections - more than just the common cold. JAMA. 2020;323(8):707-8.

2. Liu Y, Gayle AA, Wilder-Smith A, Rocklöv J. The reproductive number of COVID-19 is higher compared to SARS corona virus. Journal of Travel Medicine. 2020.

3. Niehus R, De Salazar PM, Taylor A, Lipsitch M. Quantifying bias of COVID-19 prevalence and severity estimates in Wuhan, China that depend on reported cases in international travelers. medRxiv. 2020.

4. Sitaram pandey, Amitava Samanta. Real-time forecasting of COVID-19 prevalence in India using ARIMA model International Journal of Management and Humanities (IJMH), Volume-4 Issue-10, pp 78-83, June 2020

5. Manohar Dingari, D.Mallikarjuna Reddy, V. Sumalatha Air Traffic Forecasting using Time Series Models International Journal of Recent Technology and Engineering Volume-8 Issue-4, November 2019.

6. Manohar Dingari, D. Mallikarjuna Reddy, V. Sumalatha Air Traffic Forecasting Using Artificial Neural Networks International Journal of Scientific \& Technology Research Volume 8, Issue 10, October 2019.

7. Manohar Dingari, D. Mallikarjuna Reddy, V. Sumalatha Time Series Analysis for Long Memory Process of Air Traffic Using Arfima International Journal of Scientific \& Technology Research Volume 8, Issue 10, October 2019

8. G. Baiocchi, W. Distaso, GRETL: econometric software for the GNU generation, J. Appl. Econom. 18 (2003) 105e110.

9. Y.W. Wang, Z.Z. Shen, Y. Jiang, Comparison of ARIMA and GM(1,1) models for prediction of hepatitis B in China, PloS One 13.

10. D. Mallikarjuna Reddy "Second Order Statistics of Time Series of Various Real Time Problems in Conjunction with Periodogram Technique" International Journal of Latest Trends in Engineering and Technology Vol. 3 Issue 12013

11. J. Fattah, L. Ezzine, Z. Aman, H. El Moussami, A. Lachhab, Forecasting of demand using ARIMA model, Int. J. Eng. Bus. Manag. 10 (2018).
12. S. Cao, F. Wang, W. Tam, L.A. Tse, J.H. Kim, J. Liu, Z. Lu, A hybrid seasonal prediction model for tuberculosis incidence in China, BMC Med. Inf. Decis. Making 13 (2013) 56.

13. Y.-W. Cheung, K.S. Lai, Lag order and critical values of the augmented Dickeye Fuller test, J. Bus. Econ. Stat. 13 (1995) 277e280.

14. C. COVID \& R.Team., - Severe outcomes among patients with corona virus disease 2019 (COVID-19) — United Statesl, February 12-March 16, 2020. MMWR Morb Mortal Wkly Rep, 69(12), pp. 343-346.

15. J. Gao, Z. Tian, \& X. Yang, -Breakthrough: Chloroquine phosphate has shown apparent efficacy in treatment of COVID-19 associated pneumonia in clinical studies\|, 2020, Bioscience trends.

16. D. Fanelli,, \& F. Piazza, -Analysis and forecast of COVID-19 spreading in China, Italy and Francell. Chaos, Solitons \& Fractals, 2020, 134, 109761.

17. T. Chakraborty \& I. Ghosh, (2020). —Real-time forecasts and risk assessment of novel corona virus (COVID-19) cases: A data-driven analysisll. Chaos, Solitons \& Fractals, 2020, 109850.

18. Z. Yang,, Z. Zeng,, K. Wang,, S.S. Wong, W. Liang, M. Zanin, ... \& J. Liang, - Modified SEIR and AI prediction of the epidemics trend of COVID-19 in China under public health interventions. Journal of Thoracic Diseasell, 2020, 12(3), pp 165.

19. Z. Ceylan, -Estimation of COVID-19 prevalence in Italy, Spain, and France. Science of the Total Environmentll, 2020, 138817.

20. A.A. Ariyo, A.O. Adewumi, \& C.K. Ayo, - Stock price prediction using the ARIMA modell. In 2014 UKSim-AMSS 16th International Conference on Computer Modelling and Simulation (pp. 106-112) IEEE.

\section{AUTHORS PROFILE}

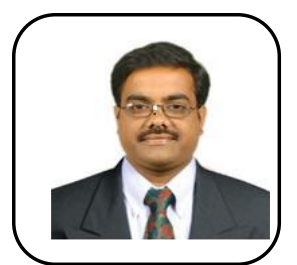

Dr D.Mallikarjuna Reddy, completed his BSc (MPC) from Kakatiya University in the yea 1995, MSc (Statistics) from Kakatiya University in the year 1998 and $\mathrm{PhD}$ from Kakatiya University, Warangal, Telangana State India in the year 2012. He has Twenty years of teaching experience including NIT Warangal, and ten years of research experience He has worked as research fellow for DST sponsored project Govt.of India under the guidance of Prof. Mallareddy Perati, Department of Mathematics Kakatiya University, Warangal. His area of research is Queuing Systems, Performance Analysis of Routers, Time Series, Organizational Culture-IT industries India and Bio-Statistics. Dr Reddy has published 35 publications in reputed international journals with one book entitled "Engineering Mathematics for Gate students, S. Chand Publishers in 2017 and chapters in other two books. Dr .Reddy received a best teacher award state level, Telangana State for the year 2016-17 from SRF foundation, Telangana. He presented his research work in 15 International conferences and participated more than 40 workshops and FDP's. He is a Reviewer and EB member for 15 international reputed journals like IEEE, IJCNDS, AIP, IANG etc. Also He acted as Treasurer for ICMSA-2019 international conference conducted by Department of mathematics GITAM Hyderabad. Under his able guidance seven research scholars perusing their Ph Ds. Two of them submitted and waiting for defense. Also, He has done data analysis using MINI TAB, SPSS, for 200 plus dissertations/project works, research articles and acknowledged. He is currently working as Assistant Professor in the Department of Mathematics, School of Science, For GITAM Deemed to be University, Hyderabad, Telangana India-502329.

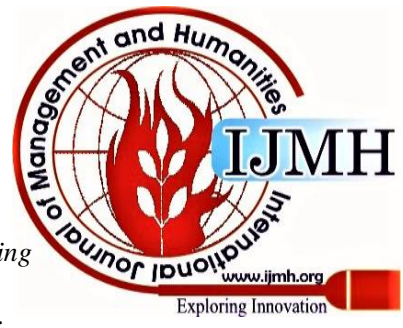

